\title{
Impact characterisation of glass fibre reinforced polymer (GFRP) type C-600 and E-800 using a drop weight machine
}

\begin{abstract}
In this study, the impact responses for GFRP type C-600 and GFRP type E-800 have been investigated. Impact tests were performed using a drop weight tester, IMATEK IM10T with eight different levels of energy ranging from $6 \mathrm{~J}$ to $48 \mathrm{~J}$. The variation of impact characteristics such as peak displacement, peak force and energy absorbed versus impact energy and damaged area were investigated. From the experimental studies, it can be concluded that for each type of GFRP, the impact energy showed excellent correlation with the impact characterization and the damaged area. The difference in the thickness and mechanical properties for both types of GFRP do affect the impact characterization and the damaged area of the specimens tested. It can be concluded that GFRP type E- 800 is higher in strength compared to GFRP type C-600.
\end{abstract}

Keyword: Drop weight test; Glass fibre reinforced polymer (GFRP); Low velocity impact (LVI) 